Michael Biggs and Daniela Büchler

\author{
School of Creative Arts \\ University of Hertfordshire \\ College Lane \\ Hatfield \\ AL10 9AB \\ UK \\ <m.a.biggs@herts.ac.uk> \\ <d.m.buchler@herts.ac.uk>
}




\begin{abstract}
Using a model of kinship from Cohen, we describe our interaction with other arts research communities, and examine our lived experiences with them over more than a decade. We refer to objective 'evidence' in the form of documentation and production, encounters and conversations, told through our own perception of our community and of the other communities. The inquiry reveals both national differences, and a variety of distinct intellectual frameworks, structures, institutional variations and limitations among arts-based research communities in UK, Canada, Australia and Scandinavia. In particular, we find in the UK-based research of Biggs and Büchler, and the Canadian-based work of Springgay, Irwin and Kind, fundamental genealogical roots that allow us to conclude that, despite their differences, they are kindred.
\end{abstract}




\section{RESEARCH INTO PRACTICE AND A/R/TOGRAPHY: A STUDY OF KINSHIP}

\section{Perceiving kinship: a journey of discovery}

Kinship describes relationships, usually between individuals and groups, as they are perceived by those involved. The social anthropologist Anthony Paul Cohen (1985) used the concept of 'boundary' to describe the construction of community. In particular he explained how the perception of boundary, and consequently of community, is a belief that motivates and guides the group. A central claim of Cohen's is that the perception of the community boundary is constructed through interaction between people - the perception of the boundary by the insider is complemented by the perception of the boundary by the outsider. The perception of community and of the relationship between communities is thus constituted through interaction between their members.

In this article we describe our interaction with other arts research communities, and examine our lived experiences with them over the years, reflecting on how that impacted on our perception of kinship between us. This perception of kinship is a commentary on the perception of what our community stands for and how we see our other more immediate communities - as close or as distant, as sharing or as isolated, as related or as acquainted. One advantage of this commentary on kinship lies in the indigenous perspective that we bring as members of one of the communities (Cuff, 1992). We therefore describe our construction of the perception of kinship by reporting on the journey which enabled and provoked that perception at given moments. We refer to objective 'evidence' in the form of documentation and production, encounters and conversations, but always told through our own perception of our community and of the other communities. In particular, the relationship between our UK description of practice-based research $(\mathrm{PbR})$ and the Canadian description of $\mathrm{a} / \mathrm{r} /$ tography seems to have enjoyed a long-lived synergy of kinship, migration and even transformation, ultimately sharing many fundamental genealogical roots. In this article we 
describe our journey of discovery of the kinship between these two groups of art researchers. This journey occurs through time and space, in which we pass some initially exciting but superficial similarities, then bump into contextual and circumstantial differences that dismay us slightly and cause us to take a course that separates the two even further, but finally, through considering the fundamental assumptions of each group more closely, we arrive at the realization that there are grounds for believing that these two are truly kindred.

\section{Identifying the family tree: similar formats}

At the University of Hertfordshire, UK, we have a group called Research into Practice ${ }^{1}$ that has be active since 2000 investigating research in the arts. The group is most visible through its organization of the biennial Research into Practice Conference series ${ }^{2}$, the Working Papers in Art and Design journal ${ }^{3}$ and, more recently, for having co-edited The Routledge companion to research in the arts (Biggs \& Karlsson, 2011). It was in 2007, when preparing the Companion and selecting reviewers for the 2008 Conference, that we conducted the literature review on which we will comment in this section and the next, with a view towards understanding the kinship between Research into Practice and A/r/tography. It bears saying that the aim of the review at the time was very focused, resulting in a tight and purposeful compilation that drew particular community boundaries. Our perception of it now, having lived the interactions that we recount here, is that the compilation itself represents a narrow range of interests and contributions. Nevertheless, reflecting on the boundaries that were drawn during the examination of the literature is germane to this article as it reveals the process of construction of the perception of boundary, and the transformation of community through interaction.

In 2007 we initially conducted searches for: 'practice-based research' and 'arts-based research', and derivative searches for: 'practice-led research', 'art-informed research', 'practice as

\footnotetext{
${ }^{1}$ http://r2p.herts.ac.uk/

${ }^{2}$ http://sitem.herts.ac.uk/artdes_research/res2prac/confhome.html

${ }^{3}$ http://sitem.herts.ac.uk/artdes_research/papers/wpades/index.html
} 
research', 'artistic research', 'artists as researchers' and other composites and Boolean keyword searches. We followed up on the authors and bibliographies of the recurring works as well as on the publishers, retailers and academic communities that had produced the emerging bibliographical compilation. The resulting database ${ }^{4}$ contains 129 titles of which $60 \%$ are journal articles, $15 \%$ conference papers, $15 \%$ books, $6 \%$ reports/unpublished papers and $4 \%$ doctoral theses. The bulk of the production was published during the decade that spanned from 1997 to 2007.

The method of conducting the literature search revealed a level of superficial similarity owing to the retrieval of diverse material from the same set of keywords. We considered this similarity to be superficial because it rested on the notion that keywords imply similar interests, areas and scope. There can be a great deal of variation in the application of keywords, leading to unreliability in the attribution of relationships between retrieved documents. The fact that 'art' and 'research' were on the menu of issues central to both communities invited the belief that there may be similar constructs at work. Not only were there words in common, but also basic relationships, such as the encounter between professional arts practice and academia. The academic context also brought with it shared themes such as the supervision and training of doctoral candidates, the design of curricula, evaluation and assessment of research, etc. At this level it was regarded as productive to identify superficial similarity in order to invite the deeper examination of materials and contexts that otherwise might not have been compared. If one thinks that one already knows who belongs in one's family tree it may blind one from seeing resemblances in individuals from faraway places. We were thus able to use the cuing that resulted from the use of common keywords as a basis for the further investigation of particular items, which would in turn feed our notions of what characterised the items we were finding.

\section{Branching out: different contexts}

\footnotetext{
${ }^{4}$ Database available for download from http://r2p.herts.ac.uk/abr/
} 
Analysis of the production found in the literature search revealed that there were geographical differences and differences in subject location within university departments. This further reinforced the superficiality of the similarities that we had inferred from the keyword search. We also identified differences in work organization and patterns of collaboration. For example, we found some degree of co-authorship, which seemed to occur more frequently within strong academic community/collegial contexts. We also found a few partnerships where there seemed to be a longstanding collaboration, e.g. Newton \& Marshall, Candy \& Edmonds, Gray \& Malins, Macleod \& Holdridge, Biggs \& Büchler, Bolt \& Barrett, Knowles \& Cole. Then there were other one-off co-authorships that seemed more tentative and to have been motivated by a larger crossinstitutional project, e.g. Grillner \& Ståhl and Till, Mottram \& Rust.

We found different clusters that were geographically distant and defended by certain groups and/or individuals. In Scandinavia, we found authors in Finland and Sweden who defended the practitioner/artist/maker's right to produce art as research (e.g. Grillner \& Ståhl, 2003; Mäkelä \& Routarinne, 2006). This position was shared by northern UK groups where we also found coauthorship and academic cooperation around the creation and development of research courses and degrees in the arts (e.g. Macleod \& Holdridge, 2005; Malins \& Gray, 2000). In the south of England we identified individuals who seemed to consider the academic strength of a practicebased $\mathrm{PhD}$ and who speculated on the conceptualization and implementation of academic norms for such (e.g. Biggs, 2002; Durling, 2002). In specific creative areas such as music, performing arts, design, architecture, multimedia, etc, we found groups that focussed on the need for developing research that feed into that practice. Such a position defended not an academicization of creative practice but a closer link between practice and academic research (e.g. Pedgley \& Wormald, 2001; Rust, 2003). It should, however, be said that the possibility of research leading to professional development in contrast to academic development is also something defined and limited by geographical and political context. Outside of the 2007 literature review, from our personal 
experience, we find that 'research' is a term that in some countries can only be applied to academic inquiry. In Brazil for example, Research and Development (R\&D), or Professional Development, are terms applicable in the non-academic context whereas 'research' always implies activities conforming to academic norms led by concepts of advancement from the empirical sciences (Biggs \& Büchler, 2012). Thus the conceivability and possibility of research leading to professional development depends on location and training, and is not an objective factor that easily enables the comparison of one research culture with another.

Another aspect of the authorship/nationality relation is that, as a result of professional migration, there seems to be much intermingling between research communities in the UK and Australia and, to a lesser degree, between the UK and Scandinavia in general. We found a number of reports and statistical mappings of practice-based research activity that were produced for funding agencies and/or university curriculum developing bodies in the UK (Rust, Mottram \& Till, 2007), Australia (Candy, 2006) and Canada (Picard-Aitken \& Bertrand, 2008). The Canadian production in our database seemed to have been more concentrated on the matters of arts education and education by artists (Cole, Neilsen, Knowles \& Luciani, 2004; Davis \& Butler-Kisber, 1999; Irwin \& de Cosson, 2004; Knowles \& Cole, 2007). Although we found that there were many aspects of the Canadian production which were compatible with that of the UK, there seemed to be limited cross-pollination between individual country's production on arts-based research.

These geographical differences are, in essence, differences in location with consequent differences in community assumptions. In the case of the UK-Canada relationship that we are investigating, we see that the intellectual frameworks that exist in each country are distinct - a distinction that is institutionalized in university structures and research councils. For example, the national funding council for arts research in Canada is the Social Sciences and Humanities Research Council (SSHRC) whereas in the UK the Council is for the Arts and Humanities (AHRC). This may account for why the arts research we found in Canada was associated to education, qualitative 
research and social sciences more generally - a link that is not present in the UK. In the UK, arts research is very much the remit of the art and design schools. Its intellectual location places emphasis on this kind of research producing artworks and, when interdisciplinarity exists, it often takes the form of Sci-Art projects (Wellcome, 2009) or art practice in the context of art therapy (McNiff, 1998).

In our journey of discovery of kinship, this distinction between intellectual frameworks arouse when we were commissioning chapters for The Routledge companion to research in the arts (Biggs \& Karlsson, 2011). We initiated dialogue with authors who we had identified in the literature search, some of whom, as we soon learned, were also contributing to a book under production in Canada: Handbook of the arts in qualitative research (Knowles \& Cole, 2007). Despite sounding similar, owing to the differences in the contextual location of each book these are actually quite different. Now that these books can be placed side by side it is easier to understand the impact of this contextual difference. The Companion is situated in the arts, and bears the voices of curators and arts practitioners. Its objectives are to construe arts practices and production as a form of knowledge. The Handbook is differently situated and bears the voices of social scientists and educators who, for the most part, argue for the arts as a source of creativity and a medium of visual representation that can extend the scope of qualitative research.

The search and preliminary review of the literature revealed another distinction that was the result of contextual location: a range of terminology, i.e. 'practice-based research', 'arts-based research', 'art-informed research', 'artists-as-researchers', 'creative researchers', 'artistic PhD', 'practice-based $\mathrm{PhD}$ ', 'arts-based $\mathrm{PhD}$ ', 'practice through research', 'practice as research', etc. In line with the Canadian SSHRC-funded Review and conceptualization of impacts of research/creation in the fine arts (Picard-Aitken \& Bertrand, 2008), we felt that there was confusion and inconsistency in the use of these terms - a situation which was also noted in the UK AHRC research review, practice-led research in art, design and architecture (Rust et al., 2007). We 
believe that this terminological abundance results in two different problems: (1) different terms used to describe similar issues/concerns albeit in different disciplines/areas, and (2) the same terms used in different disciplines/areas however describing different activities. In any case, there is a limit to what can be deduced from these two problems and it seems safe to conclude that kinship cannot be reliably inferred from terminological similarities and differences alone.

In the UK the term 'practice-based' or 'practice-led research' was used in the creative areas such as arts, design, music and performance to describe research that considered issues that emerged from the artistic practices and artworks of the professional artist. However, in nursing and general health areas practice and research focussed on how research findings could contribute to the enhancement of professional practice. Still in the UK, we found that arts therapy research used the term 'arts-based research' to describe the artistic production regardless of whether this 'artwork' was being produced by a professional artist or by a therapy patient. In Scandinavia, mainly in Sweden and Finland, the concept of 'arts-based research' was generally regarded as interchangeable with that of 'practice-based research' as understood by the creative communities in the UK. In the United States, 'practice-based research' seemed to be adopted mainly by the academic health and science communities in studies that contemplated clinical medical research or the practical activity of the researcher/scientist who was seen as conducting creative research work. In Australia, 'artsinformed research' was found to be a genre in the human sciences that was developed in response to the perceived inadequacies of conventional research methods for inquiring into and representing the complexities of human experience. Generally, the approaches were phenomenological in nature and academic inquiry in areas such as multimedia, adaptive hypermedia and HCI were amongst some of those that considered these issues. In Canada, we found that the term 'arts-informed research' was also widely used, but by the art education community. In that country, we identified research centres, universities and communities of artists that considered the contribution of artistic activity towards education, curriculum studies and the social sciences in general. Thus we found not only 
differences in context, and hence meaning and application of terminology between geographical locations, but also variation as to whether this kind of research was particular to the arts or whether, for example, what it had in common was a relationship between academic and professional values.

In terms of kinship, following the above analysis, it would seem that perhaps the various practice-based research communities around the globe were not related after all. Alternatively, if we were related we were perhaps cousins, but very far removed. If we believe that we share genetic material, we could imagine that a few generations ago the family was split up and settled in different geographic and academic contexts and as a result developed different habits and accents. If so, this would mean that any shared fundamental values were now very hidden, or perhaps lost.

\section{Unearthing common roots: corresponding contents}

With the experience of finding that, with different contexts came different assumptions and priorities, we cooled off our search for kinship for a while. The reawakening of interest came with this journal of Visual Arts Research special issue where we found, in the call for papers, many resonating interests once again. We therefore adopted the alternative hypothesis that Research into Practice and $\mathrm{A} / \mathrm{r} /$ tography were fundamentally kindred but had developed in different contexts - a hypothesis that would account for the differences identified in the previous section. We therefore embarked on an analysis of our two respective positions and have found many corresponding meanings in the underlying conceptual frameworks. In particular, the six renderings described by Springgay, Irwin \& Kind (2005) share corresponding meanings with the eight criteria for PbR that we described in Biggs \& Büchler (2008). Both articles defined each dimension of a larger theoretical framework - be it as a 'rendering' or as a 'criterion' - but were clear about the dynamic interconnectedness of these dimensions in the understanding of what is arts research to each community.

In our article 'Eight criteria for practice-based research in the creative and cultural industries' (Biggs \& Büchler, 2008) we differentiated between four ontological criteria of academic 
research and four further epistemological issues which related to the lived experience of the artist researcher. We now call the latter subject-specific $\mathrm{PbR}$ issues. Although in the 2008 article we framed these four issues in terms of the problems that arise when artists produce academic research, they serve to describe what is different about the fundamental belief system of the artist when confronted with the worldview of the traditional academic community. In this regard, the six renderings that Springgay et al present in their 2005 article, 'A/r/tography as living inquiry through art and text', describe an arts worldview that corresponds to the one described by the eight criteria and issues.

In Biggs \& Büchler (2008) we introduce four generic research criteria: question and answer, method, audience, and knowledge; and four PbR-specific issues: the role of text and image, the relationship between form and content, the function of rhetoric, and the manifestation of experience. Springgay et al (2005) introduce six renderings as: contiguity, living inquiry, openings, metaphor/metonymy, reverberations, and excess. In the remainder of this article we discuss the correspondence between the arts worldviews as presented in these two texts in order to reveal our perception of the fundamental kinship that exists between the communities of Research into Practice and A/r/tography. This is not, however, a linear correspondence (indeed there is not even a corresponding number of renderings to criteria and issues), but rather the fabric of renderings and fabric of criteria and issues describe corresponding conceptual frameworks.

The choice of articles may seem odd given that there are superficial dissimilarities and contextual similarities between them and as such they seem to serve as poor representatives of the two previous stages in our journey of discovery of kinship. However, we feel that the role that each text plays in defining arts research for each community is what makes them fundamentally similar. From the outset there is a superficial dissimilarity in the use of 'criteria'. While the Springgay et al text explicitly states that theirs is not a criterion-based approach and that $\mathrm{a} / \mathrm{r} / \mathrm{tographical}$ methodologies cannot be separated out into criteria, our text names criteria from the outset. This, 
we feel, is a dissimilarity of language and style that does not hinder the role that each text plays in helping to define the nature of arts research for each community. There is also dissimilarity in approach - where the approach of Springgay et al is aggregative, ours is reductive. By this we mean that the former text builds the description of a/r/tography through the introduction of dimensions, whereas the latter starts from an a priori description of traditional research and identifies what is missing in that description for the artist community. These dissimilarities are only superficial because, in their essence, both texts are written from within the arts research context, which is what makes them compatible and makes possible the identification of corresponding understandings.

Springgay et al call for a holistic understanding of the artist/researcher/teacher, which corresponds to our view of the artist as a holistic agent who resists having to divide their activity between what is traditional research and what is arts practice. They see agency in the in-between of duality which may account for the discomfort that we identified that the arts researcher feels with the definitiveness of a single answer, i.e. the artist perhaps finds potency in the ambiguity that accompanies plurality. Arts researchers also expressed discomfort with having to state an explicit question, which may account for why they find living a life committed to artistic inquiry agreeable.

Living inquiry adopts the language of embodiment and reflects the centrality of this kind of language to the artist. The issue of rhetoric corroborates that the language of embodiment exists in contrast to the academic language of disinterestedness and objectivity. The experiences of lived inquiry arise from what we found to be a core value of the artist community, i.e. direct encounters with artefacts. Experience through encounter enables meaning-making and brings with it philosophical subjectivity - a quality which we found to be problematic in the traditional research environment because it is not disinterested and encourages plurality of interpretations. This focus on the production of plural and unstable meaning-making is in line with the use of metaphor/metonymy which remits to what we mean by a rhetoric of arts research. The recognition of the importance of skill, in text writing and image making, is clear in our text and image struggle 
in which artist researchers seek a central role for their creations. Furthermore, the consequent importance placed on the result of skill has an impact on what we mean by rhetoric, i.e. what can be thought and known through making.

Our four criteria for academic research are presented in traditional research language, which aims to be unambiguous. The subsequent four $\mathrm{PbR}$-specific issues challenge these four criteria expressed in this language and reveal the artist-researcher's discontent with that lack of ambiguity afforded by academic requirements. Openings too, challenge the static fabric of research language in that they create disruption, opportunity for new perspectives and a temporality of meaning thus resisting the explicit and determinate structure of academic discourse. It is perhaps because art challenges linearity that we found that the artist researcher is uncomfortable with stating a specific question and answer, deciding on a method and then making an explicit contribution to knowledge. As a result, the possibility of leaving openings and gaps is agreeable to the artist researcher. Embodied versus disinterested language also served to reveal an issue with form and content for the arts researcher. We found that tension arose because, while academic discourse focuses on the form of the research output and the relevant content of the contribution to knowledge, the artist is essentially focused on the process of meaning-making which does not find resonance in traditional academic convention.

Meaning-making is central to both communities. In the a/r/tographic process this occurs through reverberation in which relational meanings are negotiated in conversation with others. Excess allows for the process of unravelling and rewriting leading to meaning-making. We found that to be relevant to the arts community, meaning-making needed to involve the audience and, as a result, was co-created. The essential dialogue between the artist/researcher/teacher and the viewer/reader remits, in our model, to the negotiation of topicality that occurs between the arts researcher and the subject-specific audience who are in a situated position to recognize and contribute to the act of meaning-making. 
We feel that this exercise of listening to the way a/r/tography voices what is arts research, has enabled us to revisit not only our previous work, identifying the implications of the eight criteria and issues for the description of the fundamental core of the arts community, but also of our previous perceptions of community boundaries and consequent kinship. The investigation of the consequences of this kinship, and the impact of context on how meanings are made and used, is a fruitful area for future research in the arts. 


\section{Acknowledgements}

The authors would like to acknowledge the Arts and Humanities Research Council (UK) for funding this research. 


\section{References}

Biggs, M. (2002). The role of the artefact in art and design research. International Journal of Design Sciences and Technology, 10(2), 19-24.

Biggs, M., \& Büchler, D. (2008). Eight criteria for practice-based research in the creative and cultural industries. Art, Design and Communication in Higher Education, 7(1), 5-18.

Biggs, M., \& Büchler, D. (2012). The meaningful exposition. In M. Schwab \& H. Borgdorff (Eds.), The exposition of artistic research: Publishing art in academia (forthcoming). Leiden: Leiden University Press.

Biggs, M., \& Karlsson, H. (Eds.). (2011). The Routledge companion to research in the arts. London: Routledge.

Candy, L. (2006). Practice-based research: A guide, from http://www.mangoldinternational.com/fileadmin/Media/References/Publications/Downloads/Practice_Based_Rese arch_A_Guide.pdf

Cohen, A. P. (1985). Symbolic construction of community. London: Routledge.

Cole, A. L., Neilsen, L., Knowles, J. G., \& Luciani, T. (2004). Provoked by art: Theorizing artsinformed research (Vol. 2): Backalong Books.

Cuff, D. (1992). Architecture: the story of practice. Cambridge, MA: MIT Press.

Davis, D., \& Butler-Kisber, L. (1999). Arts-based representation in qualitative research: collage as a contextualizing analytic strategy, Annual meeting of the American Educational Research Association. Montreal, Quebec, Canada.

Durling, D. (2002). Discourses on research and the $\mathrm{PhD}$ in design. Quality Assurance in Education, 10(2), 79-85.

Grillner, K., \& Ståhl, L.-H. (2003). Developing practice-based research in architecture and design. Nordisk Arkitekturforskning: Nordic Journal of Architectural Research, 2003(1), 15-22. 
Irwin, R. L., \& de Cosson, A. (2004). A/R/Tography: Rendering self through arts-based living inquiry. Vancouver: Canada: Pacific Educational Press.

Knowles, J. G., \& Cole, A. L. (Eds.). (2007). Handbook of the arts in qualitative research. Sage Publications, Inc.

Macleod, K., \& Holdridge, L. (2005). The enactment of thinking: the creative practice PhD. Journal of Visual Art Practice, 4(2 \& 3), 197-207.

Mäkelä, M., \& Routarinne, S. (Eds.). (2006). The art of research: Research practices in art and design. Helsinki: UIAH.

Malins, J., \& Gray, C. (2000). Educating the practice-based researcher: Developing new environments for collaborative and constructive learning. Paper presented at the Doctoral Education in Design: Foundations for the Future, La Clusaz, France.

McNiff, S. (1998). Art-based research. London: Jessica Kingsley Publishers.

Pedgley, O., \& Wormald, P. (2001). Integration of design projects within a $\mathrm{PhD}$. Design Issues, 23(3), 70-85.

Picard-Aitken, M., \& Bertrand, F. (2008). Science metrix. Review and conceptualization of impacts of research/creation in the fine arts. Ottawa, ON: Social Sciences Research Council of Canada.

Rust, C. (2003). Context - Many flowers, small leaps forward: Debating doctoral education in design. Art, Design \& Communication in Higher Education, 1(3), 141-148.

Rust, C., Mottram, J., \& Till, J. (2007). AHRC research review, practice-led research in art, design and architecture. Bristol: AHRC.

Springgay, S., Irwin, R. L., \& Kind, S. W. (2005). A/r/tography as living inquiry through art and text. Qualitative Inquiry, 11(6), 897-912.

Wellcome. (2009). Sci-Art. Retrieved 3 January 2010, from http://www.wellcome.ac.uk/Funding/Public-engagement/Past-funding/WTX035067.htm 